\title{
Clot busters! Relief of gastric outlet obstruction after Roux-en-Y gastric bypass
}

Roux-en-Y gastric bypass (RYGB) is a highly effective surgical approach for the treatment of morbid obesity [1]. Postsurgical bleeding leading to intraluminal blood clot formation causes gastric outlet obstruction (GOO) at the site of the anastomosis, and is typically managed by laparotomy or surgical revision [1,2]. Gastrojejunal clots causing GOO following laparoscopic RYGB occur in $3 \%-27 \%$ of patients [2]. Endoscopic dilation of gastrojejunal obstruction provides an alternative to surgical revision, but symptomatic relief may require up to three dilations [3, $4]$. We present a case series of three patients who developed intraluminal blood clots at the gastrojejunal anastomosis (GJA) within 72 hours of robotically assisted RYGB surgery.

The first case was a 63-year-old woman with morbid obesity (body mass index [BMI] $42 \mathrm{~kg} / \mathrm{m}^{2}$ ) who presented with persistent nausea and vomiting for 3 days after an elective RYGB. Routine upper gastrointestinal series revealed no evidence of emptying into the alimentary limb. Subsequent esophagogastroduodenoscopy revealed a large blood clot at the GJA (ه Fig. 1). After unsuccessful attempts to irrigate the clot, biopsy forceps were utilized to fragment it. In addition, an 8-mm balloon was advanced twice through the clot and inflated to successfully create a lumen ( $\bullet$ Fig. 2).

The second and third cases were a 53-yearold woman (BMI $46 \mathrm{~kg} / \mathrm{m}^{2}$ ) and a 29-yearold woman (BMI $43 \mathrm{~kg} / \mathrm{m}^{2}$ ), respectively, who presented with nausea for 3 days after RYGB surgery. Upper gastrointestinal series revealed retention of contrast in the gastric pouch, suggesting stricture at the GJA. In both patients, a $10-\mathrm{mm}$ gastroscope was used to break up the clot, and create a lumen through which passage into the alimentary limb was possible (๑ Fig. 3 and $\bullet$ Fig.4).

All three patients experienced relief of GOO without undergoing surgical revision, resulting in a shorter hospital stay and lower morbidity [4,5]. Moreover, these cases show that a single dilation may be sufficient to provide relief.

Endoscopy_UCTN_Code_TTT_1AO_2AH

\section{Competing interests: None}

\section{Kumkum S. Patel ${ }^{1}$, Jarred Marshak ${ }^{1}$, Anik M. Patel' ${ }^{2}$, James H. Grendell ${ }^{2}$, Collin E. Brathwaite ${ }^{3}$}

${ }^{1}$ Department of Internal Medicine, Winthrop University Hospital, Mineola, New York, USA

${ }^{2}$ Division of Gastroenterology, Winthrop University Hospital, Mineola, New York, USA

${ }^{3}$ Division of Surgery, Winthrop University Hospital, Mineola, New York, USA

\section{References}

1 Santo MA, Pajecki D, Riccioppo D et al. Early complications in bariatric surgery: incidence, diagnosis and treatment. Arq Gastroenterol 2013; 50: 50 - 55

2 Goitein D, Papasavas PK, Gagné D et al. Gastrojejunal strictures following laparoscopic Roux-en-Y gastric bypass for morbid obesity. Surg Endosc 2005; 19: 628-632

3 Gill RS, Whitlock KA, Mohamed R et al. Endoscopic treatment options in patients with gastrojejunal anastomosis stricture following Roux-en-Y gastric bypass. Gastroenterol Res 2012; 5: 1-5

4 Da Costa M, Mata A, Espinos J et al. Endoscopic dilation of gastrojejunal anastomotic strictures after laparoscopic gastric bypass. Predictors of initial failure. Obes Surg 2011; 21: $36-41$

5 Mala T, Søvik TT, Schou CF et al. Blood clot obstruction of the jejunojejunostomy after laparoscopic gastric bypass. Surg Obes Relat Dis 2013; 9: 234-237

\section{Bibliography}

DOI http://dx.doi.org/

10.1055/s-0034-1377544

Endoscopy 2014; 46: E470

(c) Georg Thieme Verlag KG

Stuttgart · New York

ISSN 0013-726X

\section{Corresponding author \\ Kumkum S. Patel, MD}

Department of Internal Medicine

Winthrop University Hospital

260 First Street

Apt. B13

Mineola

NY 11501

USA

Fax: +1-516-663-8796

kumkum.sarkar@gmail.com

kspatel@winthrop.org

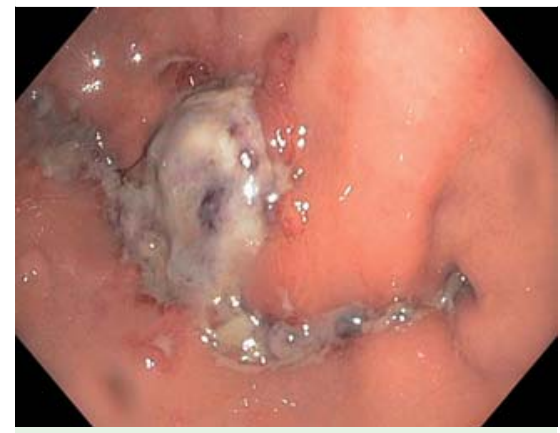

Fig. 1 Intraluminal blood clot at the gastrojejunal anastomosis.

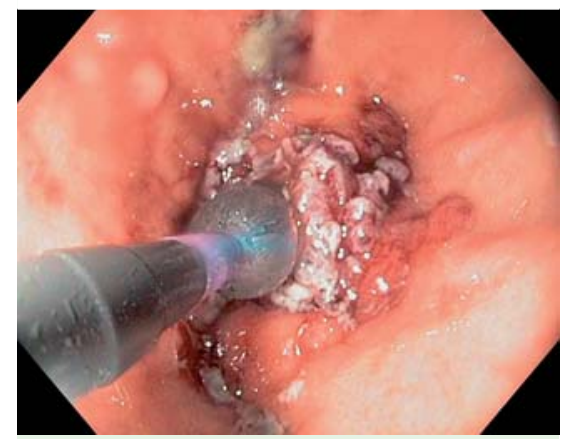

Fig. 2 Endoscopic image showing balloon dilation of the stricture made by the clot.

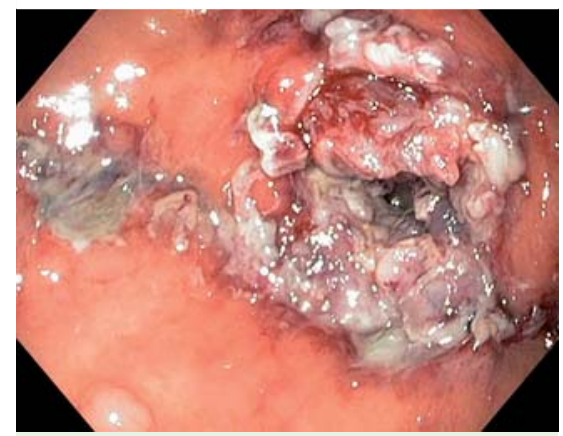

Fig. 3 Lumen created by the endoscope to relieve the obstruction.

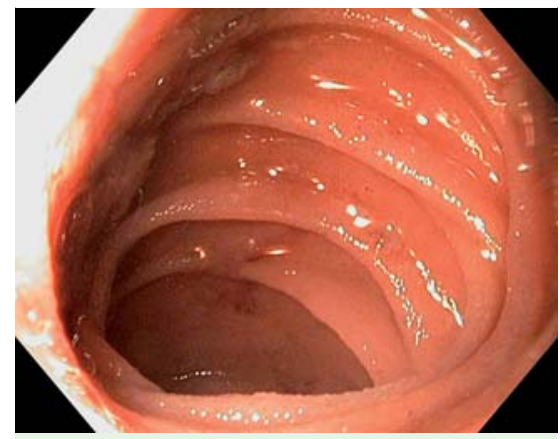

Fig.4 Passage of the endoscope into the rest of the alimentary limb after creation of the lumen. 